\title{
Purification of Rabbit Skeletal Muscle Troponin C
}

\author{
Eva Thulin ${ }^{a, *}$ and Hans J. Vogel
}

${ }^{a}$ Department of Physical Chemistry 2, University of Lund, P.O. Box 124, S-221 00 Lund, Sweden and 'Division of Biochemistry, University of Calgary, Calgary, Alberta, Canada T2N 1N4

\begin{abstract}
Thulin, E. and Vogel, H. J., 1988. Purification of Rabbit Skeletal Muscle Troponin C. - Acta Chem. Scand., Ser. B 42: 211-215.

Troponin $\mathrm{C}$ binds to phenyl-Sepharose in the presence of $\mathrm{Ca}^{2+}$ and can be eluted with EDTA. This property was used as an essential step in the purification of this protein from rabbit skeletal muscle. Troponin $C$ was extracted with $6 \mathrm{M}$ urea from extensively washed ground muscle. The protein was bound to and eluted from DEAE-Sephadex, fractionated by size on Sephadex G75, and in a final step purified from UV-absorbing non-protein impurities on phenyl-Sepharose. The total yield of electrophoretically pure protein was $60 \mathrm{mg}$ per $100 \mathrm{~g}$ of muscle, which is considerably higher than that previously obtained.
\end{abstract}

Troponin $\mathrm{C}(\mathrm{TnC})^{\dagger}$ is the calcium-binding subunit of the troponin complex that triggers the contraction of skeletal and cardiac muscle. ${ }^{1}$ The purified skeletal muscle protein has been studied in detail, and the interrelations between the binding of $\mathrm{Ca}^{2+}$ and $\mathrm{Mg}^{2+}$ and the physiological importance of the metal ion-induced conformational changes appears to be well understood. ${ }^{2-6}$ The protein has recently met with renewed interest because of the elucidation of the crystal structure,,$^{7-11}$ the availability of cloned DNA ${ }^{12,13}$ and methods for exchanging $\mathrm{TnC}$ in intact myofibrils. ${ }^{14}$

The purification of sTnC is usually accomplished in two distinct steps. First, the intact Troponin complex is purified from skeletal muscle via a series of centrifugation, precipitation and dialysis steps. The complex is then dissociated into its three subunits by treatment with $6 \mathrm{M}$ urea followed by DEAE-chromatography, ${ }^{15,17}$ or by treatment with $0.1 \mathrm{M} \mathrm{HCl}$ and $1.2 \mathrm{M} \mathrm{KCl} .^{18}$ This procedure is rather lengthy and the yields are low. It has recently been shown that purified skeletal and cardiac TnC bind to phenyl-Sepharose in a calcium-dependent manner. ${ }^{19}$ Here, we wish to report a convenient purification scheme

\footnotetext{
* To whom reprint requests should be addressed.
${ }^{\dagger}$ Abbreviations used: sTnC, skeletal muscle Troponin C; cTnC, cardiac muscle Troponin C; SDS, sodium dodecyl sulfate.

for $\mathrm{TnC}$ from rabbit skeletal muscle which, in part, makes use of this property. Similar calciumdependent hydrophobic chromatography is also used in the purification of other calcium-binding proteins such as calmodulin, ${ }^{20} \mathrm{~S} 100,{ }^{21} \alpha$-lactalbumin, ${ }^{22}$ calsequestrin ${ }^{23}$ and protein kinase C. ${ }^{24}$

\section{Materials and methods}

Phenyl-Sepharose, DEAE-Sephadex A25 and Sephadex G75 were obtained from Pharmacia and were treated as described by the supplier. Tris was from Sigma, ultra-pure urea was purchased from Schwarz-Mann and EDTA (Tritriplex III) was obtained from Merck. All other chemicals used were of analytical grade.

The purity of the preparations was analyzed by SDS-polyacrylamide electrophoresis using a gradient gel system (10-20\%), and by high resolution agarose gel electrophoresis. ${ }^{25}$ The protein on the SDS gels was stained with Coomassie Blue, and on the agarose gels as previously described. ${ }^{25}$ Protein concentrations were determined using an extinction coefficient of $\varepsilon_{280}^{1 \%}=1.93 .{ }^{16} \mathrm{UV}$ spectra were recorded on a Varian/Cary 219 spectrophotometer. Proton NMR spectra were recorded at $400 \mathrm{MHz}$ on a Bruker AM-400 WB Spectrometer. 


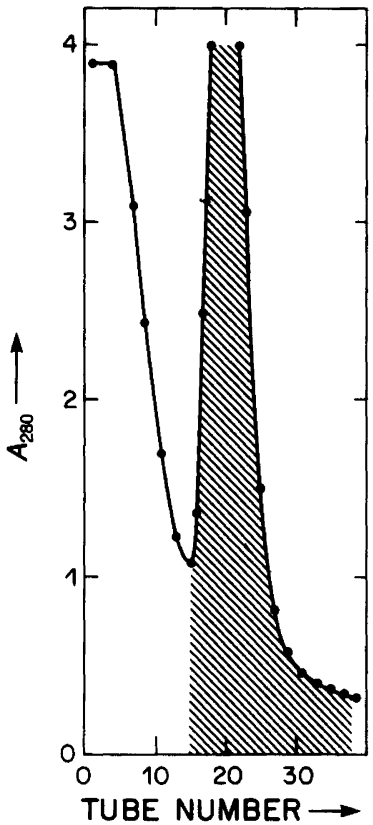

Fig. 1. Column profiles obtained with the DEAESephadex A25 column eluted with Buffer A containing $6 \mathrm{M}$ urea, and subsequently with Buffer $A$ containing both $6 \mathrm{M}$ urea and $0.7 \mathrm{M} \mathrm{NaCl}$. The fractions containing $\mathrm{STnC}$ are indicated by the hatched area and were pooled. Fractions of $10 \mathrm{ml}$ were collected. For further details, see text.

\section{Results}

Extraction. Four hundred grams of rabbit skeletal muscle were homogenized at room temperature in $2 \mathrm{l}$ of cold Buffer A $(50 \mathrm{mM}$ Tris- $\mathrm{HCl}, 0.1 \mathrm{M}$ $\mathrm{KCl}, 10 \mathrm{mM}$ EDTA, $1 \mathrm{mM} \beta$-mercaptoethanol, $\mathrm{pH}$ 7.5) using a food processor. ${ }^{26}$ The suspension was centrifuged for $15 \mathrm{~min}$ at $11,000 \mathrm{rpm}$ in a GSA-rotor in a Sorvall RC-5B centrifuge at $4^{\circ} \mathrm{C}$. The supernatant was discarded, and the pellet was resuspended in the same volume of Buffer A and homogenized and centrifuged again. The pellet was re-homogenized in cold buffer A containing $6 \mathrm{M}$ urea. This mixture was allowed to stand for $2 \mathrm{~h}$ at $4^{\circ} \mathrm{C}$. It became so viscous that it was impossible to centrifuge, and to reduce the viscosity it was therefore mixed in the food processor with 41 of cold water. This suspension was centrifuged as described above and the pellet was discarded. The supernatant was stirred for $15 \mathrm{~min}$ with $150 \mathrm{ml}$ of DEAE-Sephadex A25 and left to sediment at $4^{\circ} \mathrm{C}$ overnight. The supernatant was carefully poured off and the remaining slurry was allowed to settle in a column $(20 \times 3.5 \mathrm{~cm})$.

Purification. The column was washed with $150 \mathrm{ml}$ of Buffer A containing $6 \mathrm{M}$ urea and $0.7 \mathrm{M} \mathrm{NaCl}$. The column profile that was obtained is shown in Fig. 1. The fractions containing the $\mathrm{sTnC}$ were determined by agarose gel electrophoresis. These were pooled and dialysed against two changes of distilled water (10 l), and freeze dried. The residue was resuspended in $10 \mathrm{ml}$ of Buffer B and applied to a column $(5.5 \times 94 \mathrm{~cm})$ of Sephadex G75 which was equilibrated and eluted with Buffer B (20 mM KH $\mathrm{PO}_{4}, 1 \mathrm{mM}$ EDTA, $1 \mathrm{mM}$ $\beta$-mercaptoethanol, $\mathrm{pH}$ 7.1). The column profile obtained is shown in Fig. 2. The fractions that contained $\mathrm{sTnC}$ were determined as described before, and they were pooled. An excess of $\mathrm{CaCl}_{2}$ was added to give a final concentration of 1 $\mathrm{mM}$ and the sample was applied on a $400 \mathrm{ml}$ column containing phenyl-Sepharose suspended in Buffer C (20 mM Mops, $10 \mathrm{mM} \mathrm{NaCl}, 100 \mathrm{mM}$ $\mathrm{KCl}, 1 \mathrm{mM} \mathrm{CaCl}, 15 \mathrm{mM} \beta$-mercaptoethanol,
Fig. 2. Chromatography on Sephadex G75 of the pooled, dialyzed, lyophilized and resuspended crude sTnC obtained from the DEAE-Sephadex A25. The fraction volume was approximately $10 \mathrm{ml}$, and the fractions containing STnC are indicated by the hatched area (fractions were not collected until protein was leaving the column, one void volume).

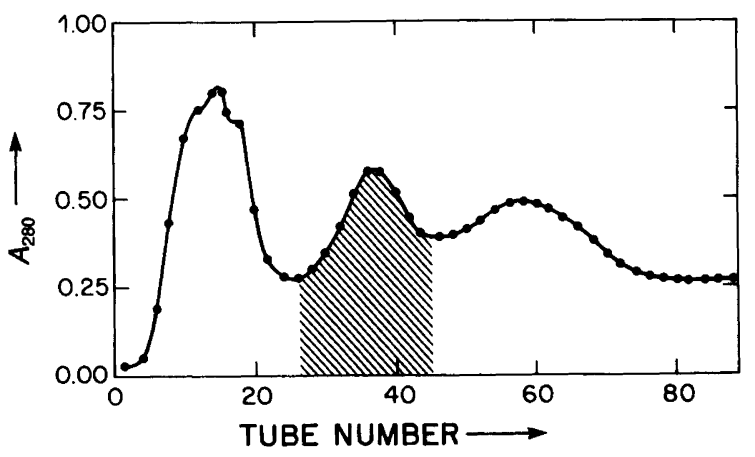




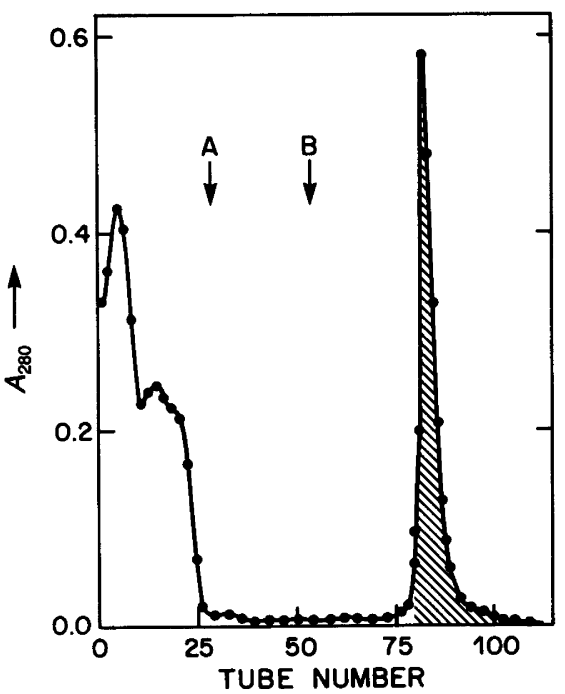

Fig. 3. Final purification of $s T n C$ during calciumdependent chromatography on phenyl-Sepharose. The arrows indicate the buffer changes as described in the text. Clearly, the protein remains attached even upon removal of the $\mathrm{Ca}^{2+}$ (arrow A) and EDTA (arrow $\mathrm{B}$ ) is necessary to complex the $\mathrm{Ca}^{2+}$ and elute sTnC (hatched area) from the column. The wash with Buffer $\mathrm{C}$ without $\mathrm{Ca}^{2+}$ can be omitted as nothing is eluted until the EDTA-containing buffer $\mathrm{C}$ is added.

$\mathrm{pH}$ 7.2). The column was first washed with 500 $\mathrm{ml}$ of Buffer C, then with $500 \mathrm{ml}$ of Buffer C without $\mathrm{Ca}^{2+}$ and finally with $500 \mathrm{ml}$ of Buffer $\mathrm{C}$ containing $3 \mathrm{mM}$ EDTA instead of the $1 \mathrm{mM}$ $\mathrm{CaCl}_{2}$. The column profile obtained in this manner is shown in Fig. 3. The total purification up to this point can be completed in less than a week. Finally, the sTnC-containing fractions obtained from the phenyl-Sepharose column were pooled, dialyzed extensively against $1 \mathrm{mM} \mathrm{CaCl}_{2}, 0.2 \mathrm{M}$ $\mathrm{NaCl}$, and then against doubly-distilled water (pH 7.0) to remove the EDTA and lyophilized. This freeze-dried protein was stable for at least one year when stored at $-20^{\circ} \mathrm{C}$.

Characterization. Fig. 4A shows the results obtained on a gradient SDS-polyacrylamide gel. Lane $G$ shows the final purified product which co-migrates with troponin $\mathrm{C}$ purified by other methods. ${ }^{15-16}$ It is clear that supernatant of the first washes (lanes A and B) and the material which does not bind to the DEAE (lane D) contain little sTnC. The protein mixture which was applied to the Sephadex G75 column contains several bands (lane E) which were not present after this chromatography step (lane F). The protein appeared essentially pure before the final phenyl-Sepharose column (compare lanes $F$ and G). A similar pattern emerged from the agarose gel electrophoresis (see Fig. 4B). Based on these two results, it appears as if the final hydrophobic interaction chromatography step may not be necessary. However, sTnC is clearly purified from some other UV-absorbing non-proteinaceous material during this step (see Fig. 3). This material could not be removed by extensive dialysis (data not shown). This is further confirmed by the UV spectra of the protein taken before and after this step. The phenylalanine fine-structure, which is a typical feature of non-tryptophan-containing proteins such as $\mathrm{sTnC}^{15}$ and calmodulin, ${ }^{27}$ can be more clearly discerned after further puri-

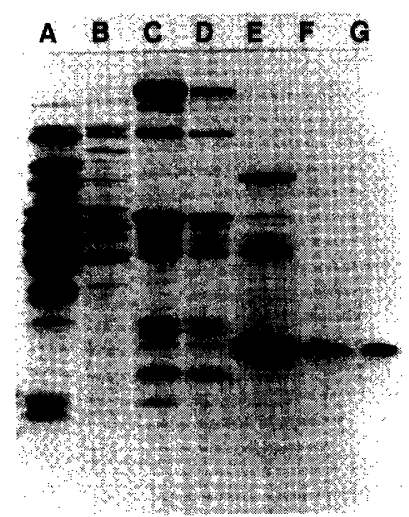

(A)

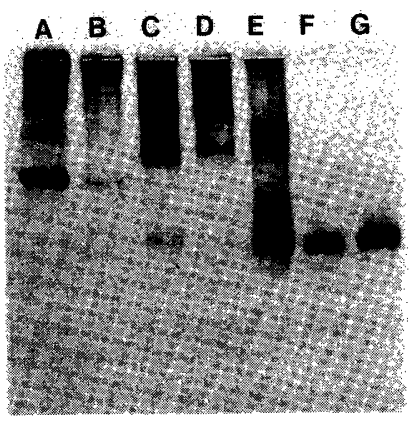

(B)
Fig. 4. (A) SDS-polyacrylamide gradient (10-20\%) gel electrophoresis, with a $4 \%$ stacking gel, of the various fractions obtained during the purification. (B) High resolution agarose gel electrophoresis of the same fractions. Lanes $A$ and $B$ : supernatant of the first two washes with buffer $A$; lane $C$ : supernatant obtained with Buffer $A$ containing $6 \mathrm{M}$ urea; lane D: the protein which does not bind to the DEAE-Sephadex; lanes E and F: protein applied and eluted, respectively, from the Sephadex G75 column; lane G: the final product. 


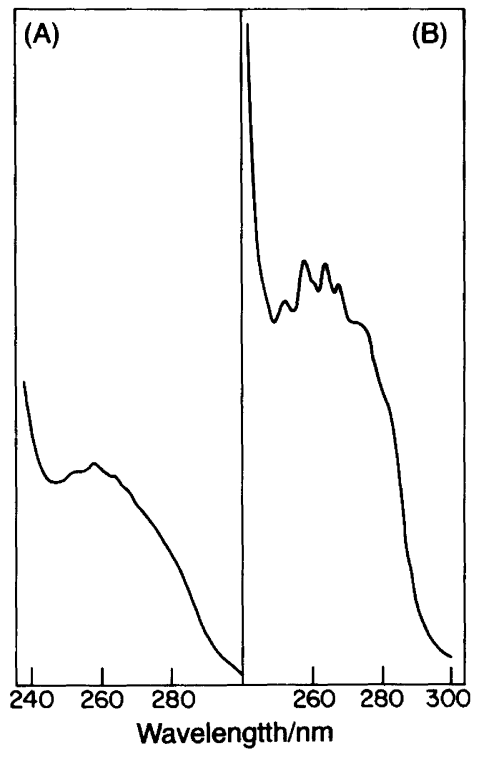

Fig. 5. UV spectra of sTnC before (A) and after (B) the final phenyl-Sepharose column. The phenylalanine fine-structure in the spectrum of the purified product can be seen clearly. Note that different protein concentrations were used to obtain these two spectra (A, $0.1 \mathrm{mg} \mathrm{ml}^{-1} ; \mathrm{B}, 2 \mathrm{mg} \mathrm{ml}^{-1}$ ).

fication on phenyl-Sepharose. The nature of the UV-absorbing material that co-purifies with the sTnC until the final phenyl-Sepharose step is not clear at present. As it does not stain with Coomassie Blue, it is unlikely that it is a protein. The absorbance maximum of $260 \mathrm{~nm}$ suggests that it could be a nucleotide. However, ${ }^{1} \mathrm{H}$ NMR studies of the early fractions eluting from the phenylSepharose column have not confirmed this. A similar impurity was also noted earlier in other TnC preparations. ${ }^{18}$ Studies are presently underway to determine the possible functional significance and the nature of this low-molecularweight endogenous substance.

TnC purified as described above gave a proton NMR spectrum ${ }^{4}$ which was indistinguishable from that of sTnC obtained by other methods ${ }^{16}$ (data not shown), further confirming the nature and purity of the protein. The total yield of electrophoretically pure sTnC was about $600 \mathrm{mg}$ per $\mathrm{kg}$ of rabbit muscle. Using previously reported purification methods, ${ }^{15-16}$ we have only been able to obtain a yield of $100 \mathrm{mg}$ per $\mathrm{kg}$.

\section{Discussion}

Although various schemes have been used for the purification of $\mathrm{sTnC},{ }^{6,15-18}$ only in one instance ${ }^{16}$ has it been shown that the protein migrates as one band in SDS-polyacrylamide gel electrophoresis and that it shows a distinct phenylalanine fine-structure in the UV spectrum. The procedure described here accomplishes the same, gives a five times better yield and represents a considerable time saving. However, with this purification scheme only the pure troponin $\mathrm{C}$ subunit is obtained, and this may be a disadvantage in cases where the other two subunits of the troponin complex are needed. Attempts to further reduce the necessary time by purifying the protein directly after the urea extraction on phenylSepharose have not been successful. For example, omission of the G75 step led to the generation of proteolytic fragments of sTnC during the calcium-dependent chromatography on phenylSepharose (data not shown). Presumably, contaminating proteases which are not active during steps performed in the presence of EDTA are still present in the preparation at this stage. This suggests that the contaminating proteolytic action is caused by $\mathrm{Ca}^{2+}$-activated proteases, which are quite abundant in skeletal muscle. The DEAE column can be replaced by a dialysis and concentration step, but we have found this more cumbersome and lengthy than the present scheme. In contrast, the final phenyl-Sepharose column step can be replaced by a batch procedure and the wash with $\mathrm{Ca}^{2+}$ absent can be deleted, which provides a further time-saving. Preliminary experiments have shown that the same purification scheme can be used to obtain homogeneous beef heart $\mathrm{cTnC}$ in high yields. The only difference between the skeletal and cardiac preparations is that the urea wash in the beef heart preparation is less viscous, eliminating the need to dilute with water before the final centrifugation step.

Acknowledgements. This project was sponsored by grants from the Swedish Natural Science Research Council (NFR) and the Canadian Medical Research Council (MRC). H.J.V. is the recipient of a Scholarship from the Alberta Heritage Foundation for Medical Research (AHFMR). 


\section{References}

1. Potter, J. D. and Johnson, J.D. In: Cheung, W. Y., Ed., Calcium and Cell Function, Academic Press, New York 1982, Vol. II, 145.

2. Potter, J. D. and Gergely, J. J. Biol. Chem. 250 (1975) 4628.

3. Leavis, P. C., Rosenfeld, S. S., Gergely, J., Grabarek, Z. and Drabikowski, W. J. Biol. Chem. 253 (1978) 5452.

4. Drakenberg, T., Forsén, S., Thulin, E. and Vogel, H. J. J. Biol. Chem. 261 (1978) 672.

5. Seamon, K. B., Hartshorne, D. J. and Bothner-By, A. A. Biochemistry 16 (1977) 4039.

6. Cox, J. A., Compte, M. and Stein, E. A. Biochem. J. 195 (1981) 205.

7. Herzberg, O. and James, M. N. G. Nature (London) 313 (1985) 653.

8. Sundralingam, M., Bergstrom, R., Strasburg, G., Rao, S. T., Roychowdhury, P., Greaser, M. and Wang, B. C. Science 227 (1985) 945.

9. Herzberg, O. and James, M. N. G. Biochemistry 24 (1985) 5298.

10. Sundralingam, M., Drendel, W. and Greaser, M. Proc. Natl. Acad. Sci. U.S.A. 82 (1985) 7944.

11. Herzberg, O., Moult, J. and James, M. N. G. J. Biol. Chem. 261 (1986) 2638.

12. Garfinkel, L. I., Periasany, M. and Nadal-Ginard, B. J. Biol. Chem. 257 (1982) 11078.

13. Putkey, J.A. and Means, A.R. In: Norman, A. W., Vanaman, T. C. and Means, A. R. Eds., Calcium-binding Proteins in Health and Disease, Academic Press, New York 1987. 267.
14. Zot, H. G. and Potter, J. D. J. Biol. Chem. 257 (1982) 7678.

15. Greaser, M. L. and Gergely, J. J. Biol. Chem. 246 (1971) 4226.

16. Greaser, M. L. and Gergely, J. J. Biol. Chem. 248 (1973) 2125.

17. Potter, J. D. Methods Enzymol. 85 (1982) 241.

18. Hartshorne, D. J., Theiner, M. and Mueller, H. Biochim. Biophys. Acta 175 (1968) 320.

19. Vogel, H. J., Lindahl, L. and Thulin, E. FEBS Lett. 157 (1983) 241.

20. Gopalakrishna, R. and Anderson, W. B. Biochem. Biophys. Commun. 104 (1982) 830.

21. Baudier, J., Holtzscherer, C. and Gerard, D. FEBS Lett. 140 (1982) 231.

22. Lindahl, L. and Vogel, H. J. Anal. Biochem. 140 (1984) 394.

23. Cala, S. E. and Jones, L. R. J. Biol. Chem. 258 (1983) 11932.

24. Walsh, M. P., Valentine, K. A., Ngai, P., Carruthers, C. A. and Hollenberg, M. D. Biochem. J. 224 (1984) 117.

25. Johansson, B. G. Scand. J. Clin. Lab. Invest. 29 (1982) 7.

26. Necessary, P. C., Roberts, D., Humphrey, P. A., Helmkamp, G. M., Turner, C. D., Rawitch, A. B. and Ebner, K. E. Anal. Biochem. 146 (1985) 372.

27. Klee, C. G. Biochemistry 16 (1977) 1017.

Received September 3, 1987. 